
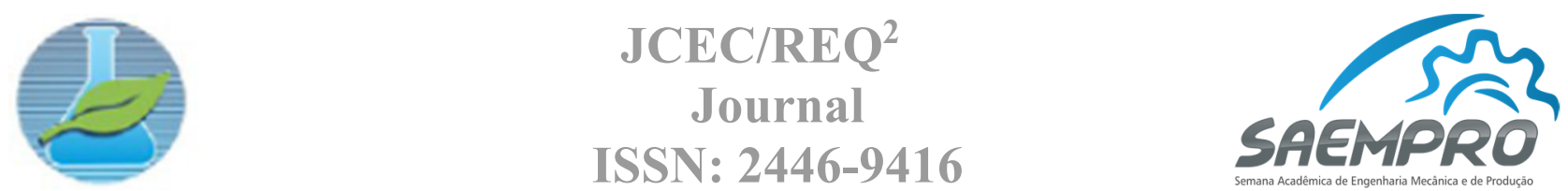

\footnotetext{
"EU, A INDÚSTRIA E O MUNDO"

08 a 11 de novembro de 2016 no campus Viçosa da UFV

Departamento de Engenharia de Produção e Mecânica - DEP

Universidade Federal de Viçosa - UFV
}

\title{
AVALIAÇÃO DOS PARÂMETROS DE RUGOSIDADE DO AÇO ABNT 1020 TORNEADO COM FERRAMENTAS DE MATERIAL DURO
}

\author{
Mauro Alberto Castheloge Rossi, Lucas Benini \\ Universidade Federal de Viçosa, Departamento de Engenharia de Produção e Mecânica \\ $\mathrm{Ph}$. Rolfs s/n - 36570-000 - Viçosa - MG \\ mauro.rossi@ufv.br, lucas.benini@ufv.br
}

\section{INTRODUÇÃO}

A fabricação de um produto pode ser realizada através de vários processos, sendo a usinagem um dos principais, além disso este processo de fabricação é uma das principais formas de produção de peças para sistemas mecânicos.

Há no mercado uma vasta gama de ferramentas de corte com variadas especificações, composições e propriedades mecânicas. Como esses processos ainda são realizados baseados na experiência, um grande número de ensaios é necessário. Por isso, a necessidade de otimização nos processos se torna evidente, principalmente no que diz respeito à velocidade de corte, uma vez que esta está diretamente relacionada ao custo da operação.

Dito isto, é preciso analisar as ferramentas disponíveis no mercado atual e propor soluções de otimização processual. Neste trabalho, tratar-se-á especificamente do processo de torneamento, com o objetivo de analisar dados de rugosidade de peças usinadas utilizando os parâmetros de corte indicados pelo fornecedor da ferramenta de corte, assim como apurar a precisão destes parâmetros para o limite de trabalho da ferramenta na usinagem do aço ABNT 1020.

\section{METODOLOGIA}

Para a realização do estudo foram utilizados um torno mecânico, operado por um técnico, além de ferramentas com variados parâmetros de corte especificados pelo fabricante. Utilizou-se de um rugosímetro, a fim de coletar dados e estes serem posteriormente analisados. Além disso, também foi utilizado um paquímetro para a medição do diâmetro e do comprimento da peça.

O material utilizado no processo foi um cilindro maciço de aço ABNT 1020, fornecido pela Universidade Federal de Viçosa, que foi torneado com ferramentas de material duro. A fim de adquirir os dados necessários para as futuras análises, foram realizados um total de cinco ensaios em dois corpos de prova. Após a preparação dos corpos, os mesmos foram fixados à máquina-ferramenta e os parâmetros de corte foram definidos. Ao final de cada passe de torneamento, o diâmetro da peça foi medido e os valores de Ra e Rz (parâmetros de rugosidade superficial) foram registrados.

No decorrer dos ensaios realizados, a velocidade de corte foi variada e em cada ensaio foi utilizada uma faixa de velocidade, devido às limitações da máquina ferramenta. Foi avaliada também a influência que outros parâmetros causariam no processo, como o avanço e a profundidade de corte. A fim de comprovar essas influências, cada parâmetro foi variado individualmente. A Tab. 1 contém os parâmetros utilizados em cada ensaio. Durante o processo, as condições ideais de corte, fornecidas pelo fabricante da ferramenta, também foram testadas. 
Tabela 1 - Parâmetros de usinagem durante os ensaios

\begin{tabular}{c|c|c|c|c}
\hline Ensaio & $\mathrm{D}(\mathrm{mm})$ & $\mathrm{V}_{\mathrm{c}}(\mathrm{m} / \mathrm{min})$ & $\mathrm{a}_{\mathrm{p}}(\mathrm{mm})$ & $f(\mathrm{~mm} / \mathrm{rev})$ \\
\hline 1 & $124.02-122,01$ & $185,04-182,07$ & 2 & 0,348 \\
\hline 2 & $120,48-90,45$ & $179,79-152,12$ & 2 & 0,19 \\
\hline 3 & $124,04-103,58$ & $292.26-244,05$ & 2 & 0,19 \\
\hline 4 & $101,54-84,32$ & $151,52-125,82$ & 2,5 & 0,19 \\
\hline 5 & $88,20-68,31$ & $207,82-160,95$ & 2 & 0,254 \\
\hline
\end{tabular}

\section{RESULTADOS}

Em um dos ensaios realizados, o parâmetro analisado foi a velocidade de corte, onde foi utilizado um valor bem menor do que a máxima fornecida pelo fabricante. Os valores de rugosidade obtidos somente ultrapassaram o máximo admitido após 16 passes de usinagem.

A velocidade de corte utilizada no primeiro passe foi $\mathrm{Vc}=179,80 \mathrm{~m} / \mathrm{min}$ e, ao decorrer do processo, ela foi diminuindo até que, no $10^{\circ}$ passe chegou à $\mathrm{Vc}=152,12 \mathrm{~m} / \mathrm{min}$. A partir deste ponto a rotação do eixo foi aumentada, resultando em uma velocidade $\mathrm{Vc}=188,31 \mathrm{~m} / \mathrm{min}$. A Tab. 2 mostra os resultados obtidos.

Tabela 2 - Dados obtidos durante o segundo ensaio

\begin{tabular}{c|c|c|c|c|c|c}
\hline Passe & $\mathrm{V}_{\mathrm{c}}(\mathrm{m} / \mathrm{min})$ & $\mathrm{a}_{\mathrm{p}}(\mathrm{mm})$ & $f(\mathrm{~mm} / \mathrm{rev})$ & $\mathrm{R}_{\mathrm{a}}(\mu \mathrm{m})$ & $\mathrm{R}_{\mathrm{z}}(\mu \mathrm{m})$ & $\mathrm{t}_{\mathrm{c}}(\mathrm{min})$ \\
\hline 1 & 179,79 & 2 & 0,19 & 7,05 & 36,18 & 1,66 \\
\hline 2 & 176,62 & 2 & 0,19 & 7,53 & 40,39 & 1,66 \\
\hline 3 & 173,59 & 2 & 0,19 & 7,53 & 40,30 & 1,66 \\
\hline 4 & 170,41 & 2 & 0,19 & 7,92 & 41,00 & 1,66 \\
\hline 5 & 167,46 & 2 & 0,19 & 8,32 & 43,15 & 1,66 \\
\hline 6 & 164,40 & 2 & 0,19 & 8,15 & 44,59 & 1,66 \\
\hline 7 & 161,32 & 2 & 0,19 & 8,07 & 42,86 & 1,66 \\
\hline 8 & 158,31 & 2 & 0,19 & 9,90 & 48,05 & 1,66 \\
\hline 9 & 155.19 & 2 & 0,19 & 10,16 & 48,99 & 1,66 \\
\hline 10 & 152,12 & 2 & 0,19 & 10,64 & 49,96 & 1,66 \\
\hline 11 & 188,31 & 2 & 0,19 & 9,35 & 49,75 & 1,31 \\
\hline 12 & 184,57 & 2 & 0,19 & 6,59 & 33,90 & 1,31 \\
\hline 13 & 180,82 & 2 & 0,19 & 7,99 & 38,45 & 1,31 \\
\hline 14 & 177,37 & 2 & 0,19 & 6,81 & 32,47 & 1,31 \\
\hline 15 & 173,77 & 2 & 0,19 & 8,53 & 45,95 & 1,31 \\
\hline 16 & 170,5 & 2 & 0,19 & 21,27 & 118,5 & 1,31 \\
\hline \hline
\end{tabular}

\section{CONSIDERAÇÕES FINAIS}

Foram realizados 5 ensaios variando-se a velocidade de corte, avanço e a profundidade de corte na usinagem do aço ABNT 1020, e através destes ensaios é possível concluir que:

- A faixa de avanço e profundidade de corte fornecidas pelo fabricante estão de acordo com os limites da ferramenta, porém a faixa de velocidade indicada está fora dos limites;

- As velocidades de corte durante os ensaios variaram de 125,82 à 292,26 m/min. Dentro deste intervalo, as velocidades que apresentaram melhor desempenho variaram de 188,31 à $152,12 \mathrm{~m} / \mathrm{min}$.

\section{REFERÊNCIAS}


CHIAVERINI, V. “Tecnologia Mecânica: Processos de fabricação e tratamento”. 2a edição. Volume 2. São Paulo: McGraw-Hill, 1986.

AMORIM, H. J. "Estudo da relação entre velocidade de corte, desgaste de ferramenta, rugosidade e forças de usinagem em torneamento com ferramenta de metal duro". 2002. Dissertação (Mestrado em Engenharia Mecânica) - Universidade Federal do Rio Grande do Sul, Porto Alegre - RS.

FREITAS, M. T. Teixeira de. "Estudo das condições de corte no resultado de trabalho do processo de torneamento do aço ABNT 1020”. Trabalho de Conclusão de Curso - Departamento de Engenharia de Produção e Mecânica, Universidade Federal de Viçosa, 2015. 